\title{
The expression of renin-angiotensin-aldosterone axis components in infantile hemangioma tissue and the impact of propranolol treatment
}

\author{
James R. Dornhoffer ${ }^{1}$, Ting Wei ${ }^{1,2}$, Haihong Zhang ${ }^{1}$, Emily Miller ${ }^{1}$, Mario A. Cleves ${ }^{1}$ and Gresham T. Richter ${ }^{1}$
}

BACKGROUND: Propranolol's mechanism of action for controlling infantile hemangioma $(I H)$ remains unclear. We hypothesize that this nonselective beta antagonist downregulates renin-angiotensin-aldosterone (RAA) axis components, preventing angiogenic substrate induction of $\mathrm{H}$.

METHODS: $I H$ tissue and serum were collected from children with propranolol-treated or -untreated $\mathrm{IH}$ during surgery. Normal skin and serum from demographically matched children were used as controls. Real-time PCR and western blot quantified RAA components in proliferative $(n=10)$, involuting $(n=10)$, propranolol-treated $(n=12) \mathrm{H}$, and normal specimens $(n=11)$. Serum was analyzed by enzyme-linked immunosorbent assay (ELISA).

RESULTS: There were significantly greater messenger RNA (mRNA) levels of angiotensinogen (AGT) in proliferating $\mathrm{IH}$, but not in involuting or treated $\mathrm{H}$, when compared with controls $(P<0.05)$. Angiotensin-converting enzyme $(A C E)$ and angiotensin II receptor 1 (AGTR1) mRNA expression was higher in all $\mathrm{IH}$ specimens when comparedwith controls $(P<0.05)$. ACE and AGTR1 protein expression was greater in proliferating $\amalg$ tissue compared with that in controls and in involuting and treated $\mathrm{H}$ tissue $(P<0.05)$. ELISA showed no significant difference in ACE serum levels but did show a significant reduction in renin in involuting compared with proliferating IH $(P<0.05)$.

CONCLUSIONS: The protein and mRNA expression of several RAA pathway constituents is elevated in $H$ tissue when compared with that in normal tissue. The action of propranolol on $\mathrm{H}$ may be the result of reductions in ACE and AGTR1.

I: nfantile hemangioma $(\mathrm{IH})$ is the most common tumor of infancy and grows by the rapid proliferation of plump endothelial cells with intervening capillaries and stroma (1-3). All IHs uniquely follow a natural cycle of growth, quiescence, and involution; however, over $40 \%$ are considered problematic and are at risk for causing impending functional deficits or disfigurement if left untreated. Both medical and surgical interventions are aimed at arresting the early growth phase of $\mathrm{IH}$ and in preventing future sequalae of proliferating lesions. Historic interventions include laser ablation, regional or systemic steroids, or surgical excision.

Recently, low-dose nonselective and selective beta blockade has been shown to induce or accelerate the involution of IH in up to $97 \%$ of cases and as early as 1-2 days of starting therapy (2-7). Thus, propranolol, an inexpensive nonselective beta blocker, has become the mainstay for treating problematic IH (2-7). Propranolol's mechanism of action remains uncertain. Several studies have suggested a variety of biological pathways affecting endothelial and vascular stability. Angiogenic factors, such as vascular endothelial growth factor, endothelial nitric oxide synthase, and hypoxia-inducible factor, have been implicated in both the natural history and treatment of IH $(2-4,8,9$.$) In addition, the renin-angiotensin-aldosterone$ (RAA) pathway has been shown to be involved in the regulation of many of the angiogenic factors and processes implicated in IH development (10-17).

The RAA pathway is an enzymatic pathway involved in multiple physiologic processes. Its primary action has been to influence blood pressure regulation, hemodynamic forces, and renal function, and its primary constituents include various proteins (renin, angiotensinogen, etc.) and their receptors (18). Medications used to block this pathway as therapeutic interventions include angiotensin-converting enzyme (ACE) inhibitors and angiotensin II receptor 1 (AGTR1) blockers. The secretion of renin, the initiating protein in the RAA pathway, can be modulated by beta-1 agonists or reduced by nonselective and selective beta- 1 antagonists, such as propranolol. Thus, the mechanisms by which propranolol affects IH growth may be linked to the RAA pathway.

Experimental evidence suggests that IHs arise from aberrant or embolic hematopoietic stem cells that exhibit the molecular markers of early cell differentiation of placental tissue $(2,4,19-22)$. Ectopic transplantation of early placental progenitors, via trauma or physical translocation, has therefore been proposed as the source of IH. Similarly, aberrant neural crest cell

\footnotetext{
'Department of Otolaryngology-Head and Neck Surgery, University of Arkansas for Medical Sciences, Little Rock, Arkansas. Correspondence: J.R. Dornhoffer 


\section{Articles | Dornhoffer et al.}

migration, which can carry placental cells and seed broad regions, is thought to contribute to the development of large, segmental IHs (23-25). Many components of the RAA axis are strongly expressed in placental tissue, for the purposes of maternal-fetal blood flow regulation (26-28), and may provide the necessary signaling for the growth of $\mathrm{IH}$ from seeded placental cell progenitors.

IHs are more common in premature infants, female infants, and infants of multiple gestation, as well as in certain conditions such as gestational hypertension and preeclampsia $(1,2)$. These represent states of potentially hyperactive RAA axis pathways (20-31), whereas the growth and involution of IH mirror physiological changes in renin levels in the newborn (32-35). In particular, renin levels are elevated over the period during which $\mathrm{IH}$ growth is most rapid in the newborn, but they reduce and normalize as IH begins to involute $(5,36)$.

Recent reports on the role of the RAA axis in the physiology of IH have shown angiotensin II (AGTII), a major product in the RAA axis, to be involved in both $\mathrm{IH}$ and mesenchymal cell lines (10-17). Specifically, AGTII can induce vascular cell growth in culture, and its action can be blocked at the level of its receptor or with ACE (15). In addition, RAA axis components have been shown to be present in IH tissue, and excision of IH tissue has been shown to lower serum levels of these factors in vivo $(16,17)$. Propranolol activity in the treatment of IH has been well documented (2,3,5-7). However, selective beta-1 blockers, such as atenolol, and ACE inhibitors, such as captopril, have also been shown to have efficacy in the treatment of $\mathrm{IH}(37,38)$. Both of these medications have a large physiological effect grounded in the RAA axis, by either reducing renin secretion through beta-1 blockade or at the level of conversion of AGTI to AGTII. Propranolol, having both beta-1- and beta-2-blocking capacity, will also have an impact on normal RAA axis regulation, and this may subsequently explain its mechanism of action in treating $\mathrm{IH}$.

Thus, the RAA pathway is involved in many prenatal and postnatal processes, perinatal conditions, and vascular cell growth, although its role in $\mathrm{IH}$ growth and propranolol therapy is not clearly defined. We believe that components of the RAA pathway affect the natural history of $\mathrm{IH}$ and, if so, would explain the action of propranolol and other nonselective and selective beta blockers on their growth. This study thereby examines the role of the RAA pathway, rudimentarily demonstrated in Figure 1, in both the natural and propranolol treatment course of $\mathrm{IH}$. We hypothesized that propranolol inhibits beta-1-dependent regulation of renin, which acts to downregulate the RAA axis and possibly reduce the generation and activity of end products shown to induce angiogenic cofactors and could explain the early involution of IH $(10,11)$.

\section{METHODS}

\section{Samples}

This study was approved by the University of Arkansas for Medical Sciences Institutional Review Board. Normal tissue and discrete IH tissue samples were obtained intraoperatively from patients

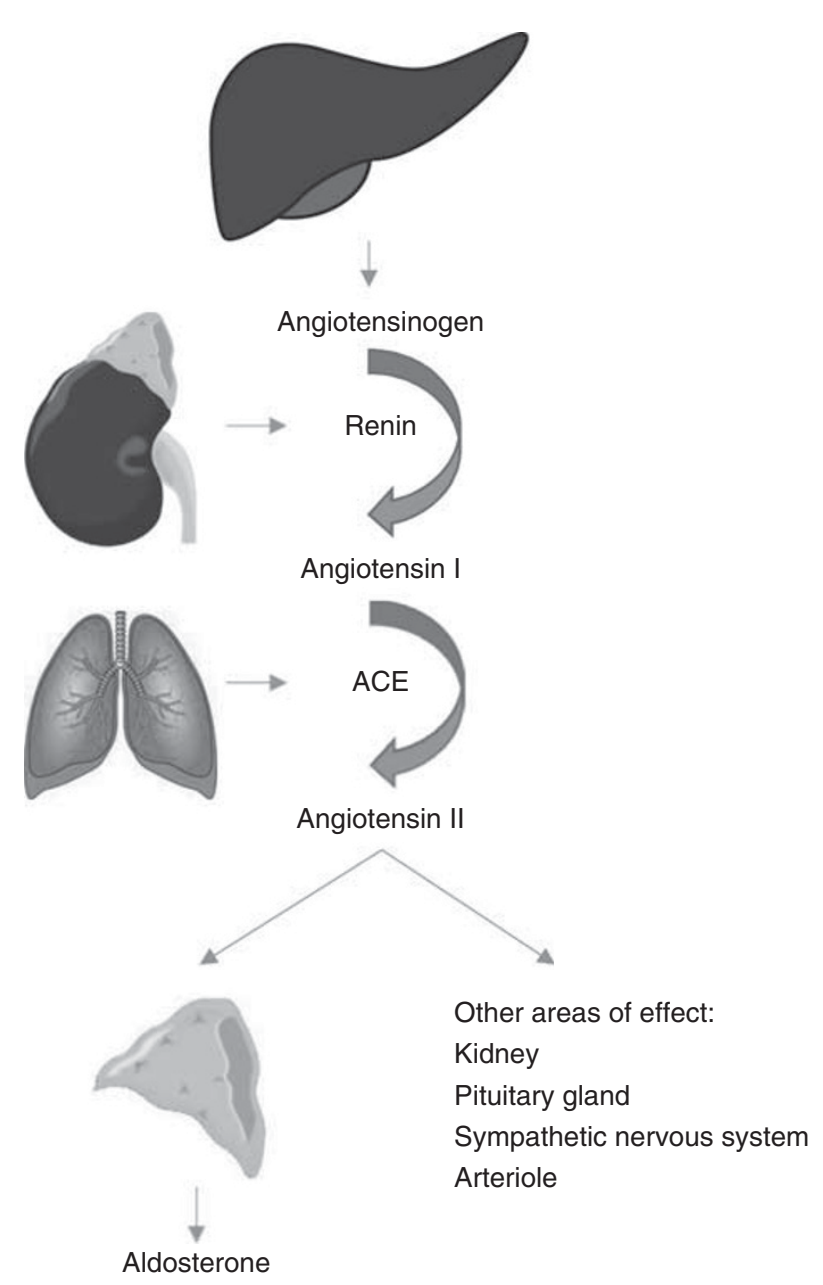

Figure 1. The RAA axis. Angiotensinogen from the liver is metabolized by renin from the kidney juxtaglomerular apparatus to angiotensin I, which is metabolized by ACE to angiotensin II. Angiotensin II acts both directly in tissue through its receptors and indirectly through the inductions of aldosterone.

undergoing surgical treatment for $\mathrm{IH}$ in both head and neck and torso locations. The propranolol-treated IH samples were taken from $\mathrm{IH}$ patients showing partial response or ulcerative lesions that reduced in size but anticipated retained cosmetic defect due to skin injury by ulcer. Early intervention was taken to improve overall outcome with propranolol. Normal tissues were obtained from the margin of the surgical site. The consent of patients providing samples was properly taken as per the terms of the University of Arkansas for Medical Sciences Institutional Review Board. All IH samples were identified as such with GLUT1 staining and were designated as proliferating, involuting, or propranolol-treated with respect to patient age, clinical history, and pathology. All tissues were snapfrozen on dry ice and stored at $-80^{\circ} \mathrm{C}$ until analysis. The numbers and demographics of these patients are listed in Table 1.

Serum samples for use in enzyme-linked immunosorbent assay were obtained via venipuncture from a similar clinical patient population as detailed in Table 1 . In this case, normal samples came from patients without IH. IH status in patients was determined in the same matter as that used for the tissue sample population. Processing procedures are detailed below.

\section{Quantitative Reverse Transcription PCR}

Approximately $30 \mathrm{mg}$ of each tissue sample was used for RNA isolation with the RNeasy Plus Kit (Qiagen, Hilden, Germany, 
Table 1. Demographics of the sample populations

\begin{tabular}{|c|c|c|c|c|c|}
\hline \multicolumn{6}{|c|}{ Kruskal-Wallis equality-of-populations rank test for western blot experiment } \\
\hline & All & Normal & Involuting & Proliferating & Propranolol treated \\
\hline \multicolumn{6}{|l|}{ qPCR samples } \\
\hline$N$ & 43 & 11 & 10 & 10 & 12 \\
\hline Age (months), mean (SD) & $13.84(8.51)$ & $9.61(3.35)$ & $21.95(5.97)$ & $7.12(2.51)$ & $16.57(10.26)$ \\
\hline Percent female & 76.74 & 90.90 & 60 & 80 & 75 \\
\hline Treatment length (months), mean (SD) & & & & & $7.68(5.18)$ \\
\hline \multicolumn{6}{|l|}{ Western blot samples } \\
\hline$N$ & 63 & 13 & 19 & 18 & 13 \\
\hline Age (months), mean (SD) & $14.36(8.74)$ & $10.08(4.00)$ & $21.95(5.97)$ & $7.12(2.51)$ & $16.56(10.33)$ \\
\hline Percent female & 76.19 & 76.92 & 68.42 & 77.78 & 84.61 \\
\hline Treatment length (months), mean (SD) & & & & & $7.51(4.94)$ \\
\hline \multicolumn{6}{|l|}{ ELISA samples } \\
\hline$N$ & 32 & 8 & 8 & 8 & 8 \\
\hline Age (months), mean (SD) & $18.17(11.54)$ & $24.48(11.09)$ & $25.64(12.83)$ & $8.73(5.21)$ & $13.84(6.49)$ \\
\hline Percent female & 71.88 & 75 & 75 & 75 & 62.5 \\
\hline Treatment length (months), mean (SD) & & & & & $8.92(4.26)$ \\
\hline
\end{tabular}

ELISA, enzyme-linked immunosorbent assay; $\mathrm{PPCR}$, quantitative PCR.

cat. no. 74134). All RNA samples were then converted into complementary DNA using the TaqMan Reverse Transcription Reagents Kit (Life Technologies, Carlsbad, CA, cat. no. 4304134) and random primers according to the manufacturer's instruction. Real-time PCR amplifications were performed on the ABI 7900HT System (Applied Biosystems, Foster City, CA). Thermal cycling conditions were as follows: 1 cycle of $50{ }^{\circ} \mathrm{C}$ for $2 \mathrm{~min}, 1$ cycle of $95^{\circ} \mathrm{C}$ for $10 \mathrm{~min}$, followed by 40 cycles of $95^{\circ} \mathrm{C}$ for $15 \mathrm{~s}$ and $60^{\circ} \mathrm{C}$ for $1 \mathrm{~min}$ each. The total reaction volume of $10 \mu \mathrm{l}$ contained $5 \mathrm{ng}$ of complementary DNA template, $5 \mu \mathrm{l}$ of $2 \times$ PCR Master Mix (Life Technologies, cat. no. 4304437), and $0.5 \mu \mathrm{l}$ of $20 \times$ primers/probe of target genes or endogenous control assay mix. Eukaryotic $18 \mathrm{~S}$ ribosomal RNA (Life Technologies, Hs99999901_s1) was used as the endogenous control. The comparative $C t$ method was used to determine relative quantification. The amplification amount of all target genes was normalized against that of $18 \mathrm{~S}$ ribosomal RNA. Our target genes were as follows: REN for renin (Life Technologies, Hs00982555_m1), $A C E$ for angiotensin-converting enzyme I (Life Technologies, Hs00174179_m1), ACE2 for angiotensin-converting enzyme II (Life Technologies, Hs01085333_m1), AGT for angiotensinogen (Life Technologies, Hs01586213_m1), AGTR1 for angiotensin II receptor 1 (Life Technologies, Hs00258938_m1), and AGTR2 for angiotensin II receptor 2 (Life Technologies, Hs02621316_s1).

\section{Western Blot Analysis}

Total proteins were extracted using the T-PER tissue protein extraction reagent (Thermo Scientific, Waltham, MA) added with Halt Protease Inhibitor Cocktail (Thermo Scientific) and $1 \mathrm{mM}$ EDTA (Invitrogen, Carlsbad, CA). Protein concentrations were measured using a BCA protein assay kit (Thermo Scientific). Total protein $(20 \mu \mathrm{g})$ was loaded onto NuPAGE Novex $4-12 \%$ Bis-Tris Protein Gels (Invitrogen) for electrophoresis under reducing conditions and transferred to polyvinylidene difluoride membranes (Bio-Rad, Hercules, CA). The membranes were blocked with 5\% non-fat milk in Tris Buffered Saline with Tween (TBST) for $1 \mathrm{~h}$ at room temperature, followed by incubation with primary antibodies at $4{ }^{\circ} \mathrm{C}$ overnight. Blots were washed with TBST three times, followed by incubation with horseradish peroxidase-conjugated secondary antibodies (Santa Cruz Biotechnology, Dallas, TX, 1:2,000) for $1 \mathrm{~h}$ at room temperature. Blots were developed using Novex ECL Chemiluminescent Substrate Reagent Kit (Invitrogen) in the dark and exposed on film (Thermo Scientific). Film pictures were taken with Image Quant LAS 4000 (GE Healthcare, Little Chalfont, UK), and image results were analyzed with Image Quant TL 7.0 software (GE Healthcare). Our primary antibodies and concentrations were as follows: ACE (Santa Cruz Biotechnology, SC-20791, 1:200), AGTR1 (Santa Cruz Biotechnology, SC-1173, 1:200), angiotensin I (AGTI, Santa Cruz Biotechnology, SC-80682, 1:200), and AGTII (Novus Biologicals, Littleton, CO, NB100-62346, 1:400). Results were normalized against GADPH.

\section{Enzyme-Linked Immunosorbent Assay}

Peripheral whole blood samples were obtained from venipuncture and centrifuged at $1,000 \mathrm{~g}$ for $15 \mathrm{~min}$ after $30 \mathrm{~min}$ of clotting at room temperature. Serum was transferred, aliquoted, and stored at $-80^{\circ} \mathrm{C}$ until analysis. Serum levels of renin and ACE were determined according to the manufacturer's instructions (R\&D Systems, Minneapolis, MT). Optical density was read on an iMark microplate absorbance reader (Bio-Rad).

\section{Data Analysis}

All samples were run in triplicate and quantified using the methods mentioned above. Analysis was undertaken using the Kruskal-Wallis equality-of-populations rank test to determine overall difference for each target gene product or protein. Additional testing was done using Bonferroni-adjusted $P$ values from post hoc Dunn's pairwise comparison test to determine intragroup differences. Significance was designated as $P<0.05$. We have chosen not to use age-adjusted values because of the fact that age plays a known role in the expression of certain RAA factors and, as such, acts as part of the natural history of $\mathrm{IH}$, which we wish to study, rather than as a confounding factor (23-26). All analyses were performed and approved by a house statistician. 


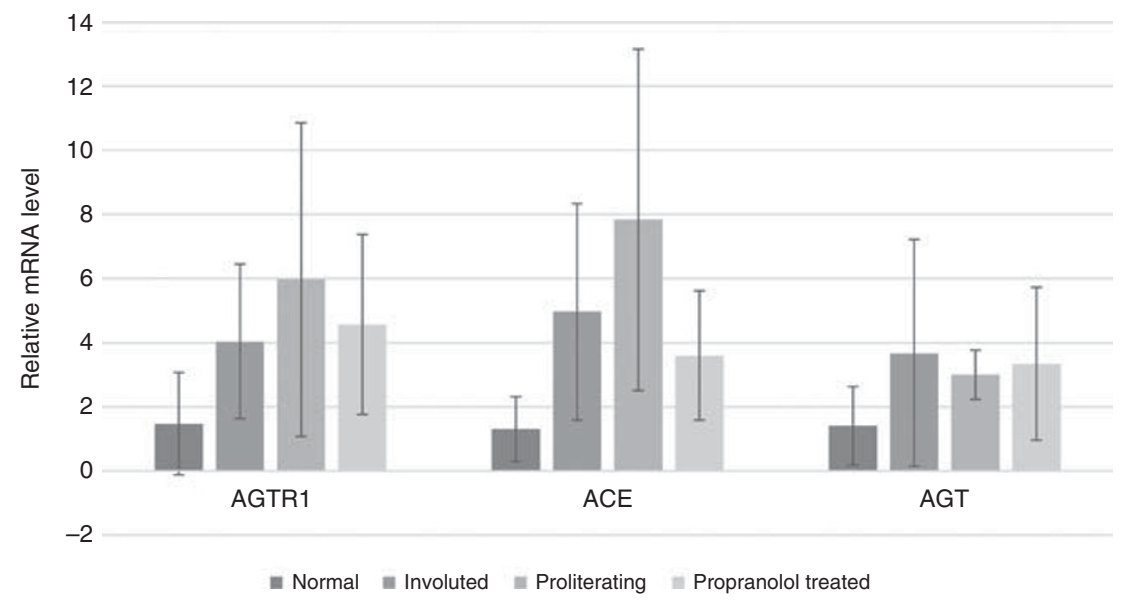

Figure 2. Quantitative real-time PCR analysis of RAA constituents in $\mathrm{IH}$ and normal tissue. mRNA levels of ACE and AGTR1 are increased in proliferating, involuting, and propranolol-treated IH tissue compared with normal tissue. mRNA levels of $A G T$ are also significantly increased in proliferating $\mathrm{IH}$ tissue compared with normal tissue. Renin, ACE2, and AGTR2 showed no amplification and, as such, are not listed above.

Table 2. Statistical analysis of qPCR analysis of RAA axis components in IH and normal tissue

\begin{tabular}{|c|c|c|c|c|c|c|}
\hline \multicolumn{7}{|c|}{ Kruskal-Wallis equality-of-populations rank test for qPCR experiment } \\
\hline & All & Normal & Involuting & Proliferating & Propranolol treated & $P$ value \\
\hline \multicolumn{7}{|l|}{ AGTR1 } \\
\hline Median (IQR) & $3.52(2.72)$ & $0.48(3.21)$ & $4.03(1.88)$ & $4.14(4.35)$ & $3.86(2.19)$ & 0.0084 \\
\hline Median (IQR) & $3.20(4.49)$ & $0.97(1.58)$ & $3.86(2.98)$ & $8.16(7.19)$ & $2.87(2.47)$ & 0.0005 \\
\hline \multicolumn{7}{|l|}{ AGT } \\
\hline$N$ & 43 & 11 & 10 & 10 & 12 & \\
\hline AGTR1 & & & & 1.0000 & 0.0139 & \\
\hline ACE & & & & 1.0000 & 0.0317 & \\
\hline AGT & & & & 1.0000 & 0.0792 & \\
\hline
\end{tabular}

ACE, angiotensin-converting enzyme; AGT, angiotensinogen; AGTR1, angiotensin II receptor 1; IH, infantile hemangioma; IQR, interquartile range; qPCR, quantitative PCR; RAA, renin-angiotensin-aldosterone.

Statistical significance was defined as $P<0.05$. Significant relationships in the analysis above are in bold type.

\section{RESULTS}

\section{Quantitative Real-Time PCR}

Results are detailed in Figure 2 as the mean mRNA level along with SE of each sample group ascertained using the comparative $C t$ method for quantitative PCR for the genes AGTR1, ACE, and AGT (angiotensinogen), which encodes the precursor protein to AGTI and AGTII. There was no amplification of the mRNA product for REN (renin), ACE2 (angiotensin-converting enzyme 2), or AGTR2 (angiotensin II receptor 2), and, as such, these gene products are not listed.

Statistical analysis of these results is detailed in Table 2 . There was a significant difference among the sample groups for AGTR1, ACE, and AGT $(P=0.0084, P=0.0005$, and $P=0.0291$, respectively). Post hoc analysis showed significantly elevated levels of AGTR1 in involuting, proliferating, and propranolol-treated $\mathrm{IH}$ tissue compared with normal tissue ( $P=0.0377, P=0.0095$, and $P=0.0139$, respectively). Similarly, significantly elevated levels of $A C E$ were found in 


\section{RAA axis in infantile hemangioma}

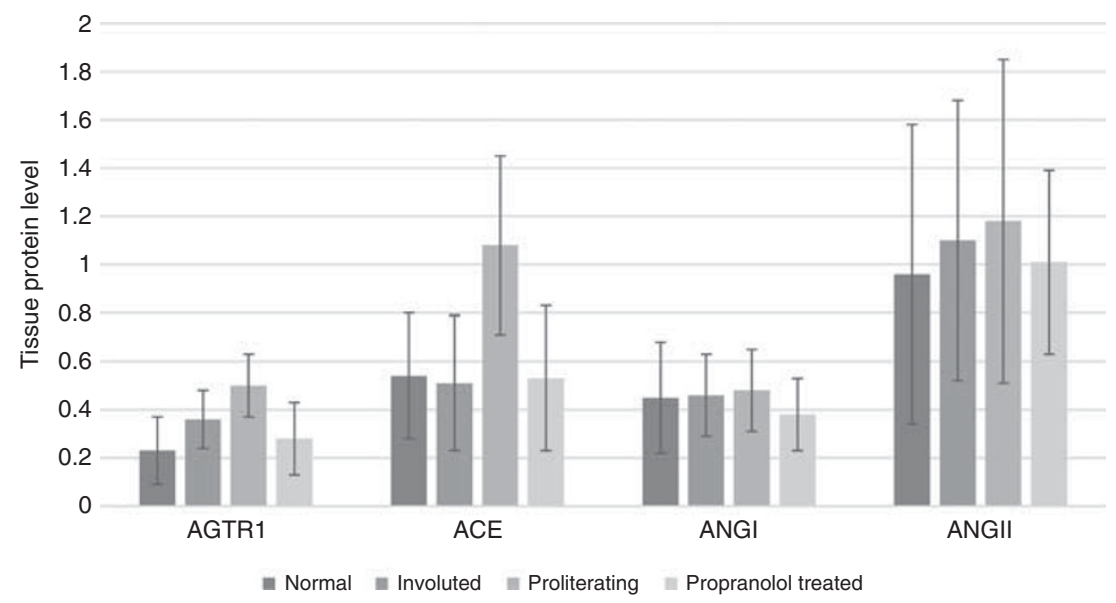

Figure 3. Western blot of RAA constituents in IH and normal tissue. Levels of ACE and AGTR1 are elevated in proliferating IH tissue compared with those in normal tissue and other types of IH tissue. Levels of angiotensin I and angiotensin II show no significant changes.

involuting, proliferating, and propranolol-treated $\mathrm{IH}$ tissue compared with normal tissue $(P=0.0054, P=0.0002$, and $P=0.0317$, respectively). Finally, a significant elevation in AGT mRNA was found in proliferating IH tissue compared with normal tissue $(P=0.0229)$.

\section{Western Blot Analysis}

Results are detailed in Figure 3 as the mean protein level along with SE as determined by the fluorescence level of each sample group, normalized against GADPH, using the methods detailed in the appropriate section. Proteins chosen for western blot analysis included AGTR1, ACE, AGTI, and AGTII. Because of the lack of amplification of the mRNA product for REN, ACE2, or AGTR2, these protein products were exempt from further examination. Results of the analysis are detailed in Table 3. There was a significant difference among the sample groups with respect to AGTR1 and ACE $(P<0.0001$ and $P<0.0001$, respectively). No significant differences were noted for levels of AGTI or AGTII $(P=0.4561$ and $P=0.8158$, respectively). Post hoc analysis showed significantly elevated levels of AGTR1 and ACE in proliferating IH tissue compared with normal tissue, involuting $\mathrm{IH}$ tissue, and propranolol-treated $\mathrm{IH}$ tissue $(P<0.0001$, $P=0.0351$, and $P=0.0009$, respectively, for AGTR1; $P=0.0004, P<0.0001$, and $P=0.0006$, respectively, for ACE).

\section{Enzyme-Linked Immunosorbent Assay}

Results are detailed in Figure 4 as the mean of optical density of each sample group along with SE as ascertained by the methods detailed in the appropriate section.

The results of the analysis are detailed in Table 4 and show a significant change among the sample groups for renin $(P=0.0124)$. No such significance was noted among the sample groups for ACE $(P=0.8979)$. Post hoc analysis showed the serum levels of renin in patients with involuting $\mathrm{IH}$ to be significantly lower than those in patients with proliferating $\mathrm{IH}$ $(P=0.0035)$.

\section{DISCUSSION}

Experimental and clinical evidence has demonstrated RAA pathway components to be involved in perinatal, placental, and vascular processes. The present study provides a detailed analysis of protein and mRNA expression of the RAA axis in $\mathrm{IH}$, at various stages of growth and treatment, with controlled comparisons. Results from this work indicate the role of various components of the RAA pathway in the etiology of $\mathrm{IH}$ and the impact of its most important medical therapy. In particular, mRNA expression of ACE and AGTR1 was elevated in IH compared with demographically matched normal samples. We also showed that protein levels of ACE and AGTR1 are higher in proliferating IH compared with those in the involuting or propranolol-treated counterparts. Serum levels of ACE, a major soluble enzyme in the RAA pathway, did not change with involution or treatment of IH. However, reductions in renin serum levels suggest a possible age-related change in renin in involuting $\mathrm{IH}$.

ACE and AGTR1 generate or transduce the effect of AGTII, which has been shown to induce IH growth in culture and to induce RAA axis components in endothelial cells (13-15). The anticipated difference in AGTII levels among our study groups, however, was not demonstrated, but it could be explained by the in vitro breakdown of localized AGTII spikes by local proteolytic enzymes called angiotensinases. The activity of these enzymes gives AGTII a half-life of just minutes (18). This study may have been unable to capture and process specimens with sufficient time to detect a local difference between samples with respect to AGTII. Also, regardless of AGTII levels, we postulate that increased AGTII activity may still be evidenced by elevated levels of its receptor, AGTR1, which our study did show.

Mesenchymal stem cell cultures demonstrated the induction of hypoxia-inducible factor by AGTII, a known mediator of vascular growth in IH. Hypoxia-inducible factor has been shown to induce vascular endothelial growth factor and other downstream angiogenic factors to cause endothelial and 


\section{Articles | Dornhoffer et al.}

Table 3. Statistical analysis of western blot analysis of RAA axis components in IH and normal tissue

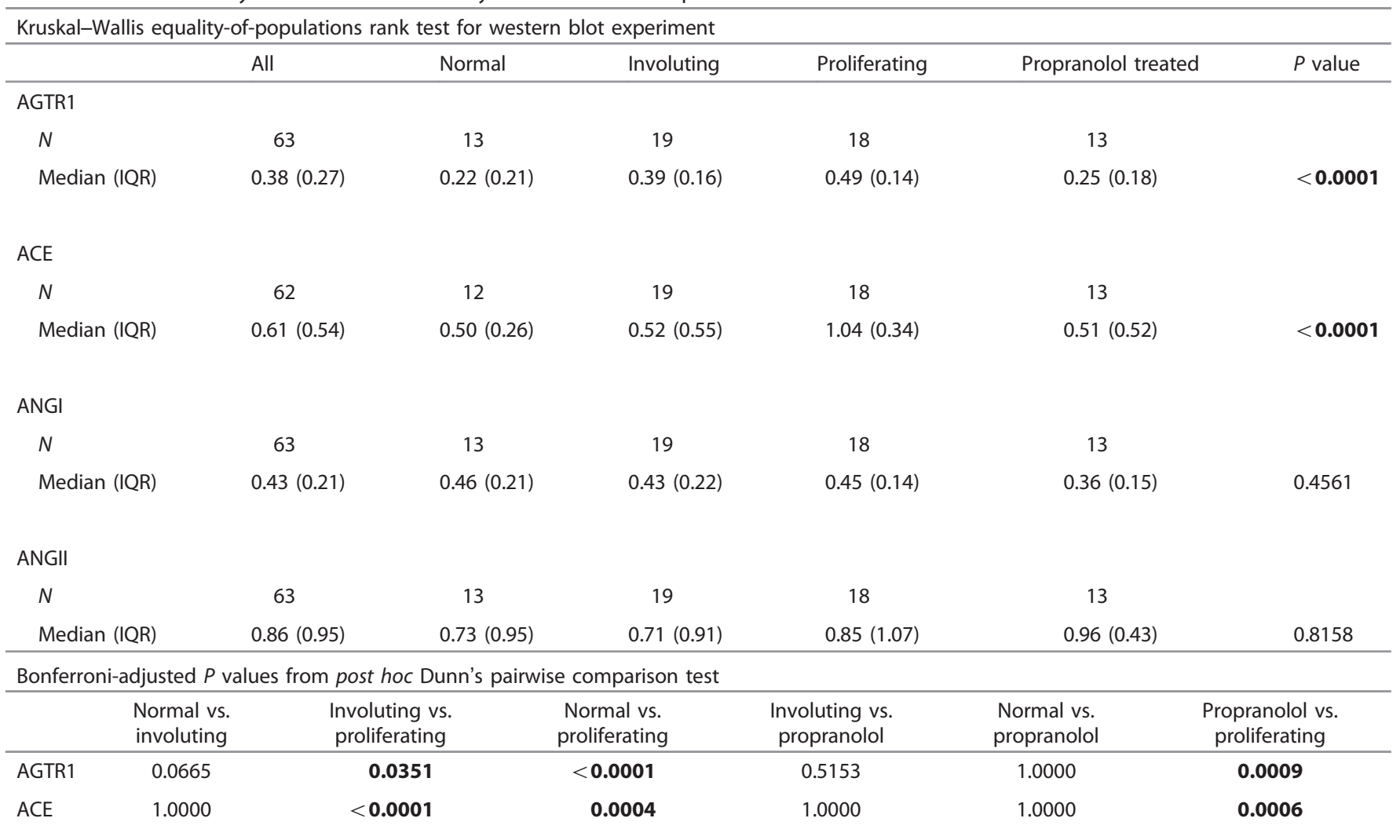

ACE, angiotensin-converting enzyme; AGTR1, angiotensin $\|$ receptor $1 ; \| \mathrm{H}$, infantile hemangioma; IQR, interquartile range; RAA, renin-angiotensin-aldosterone.

Statistical significance was defined as $P<0.05$. Significant relationships in the analysis above are in bold type.

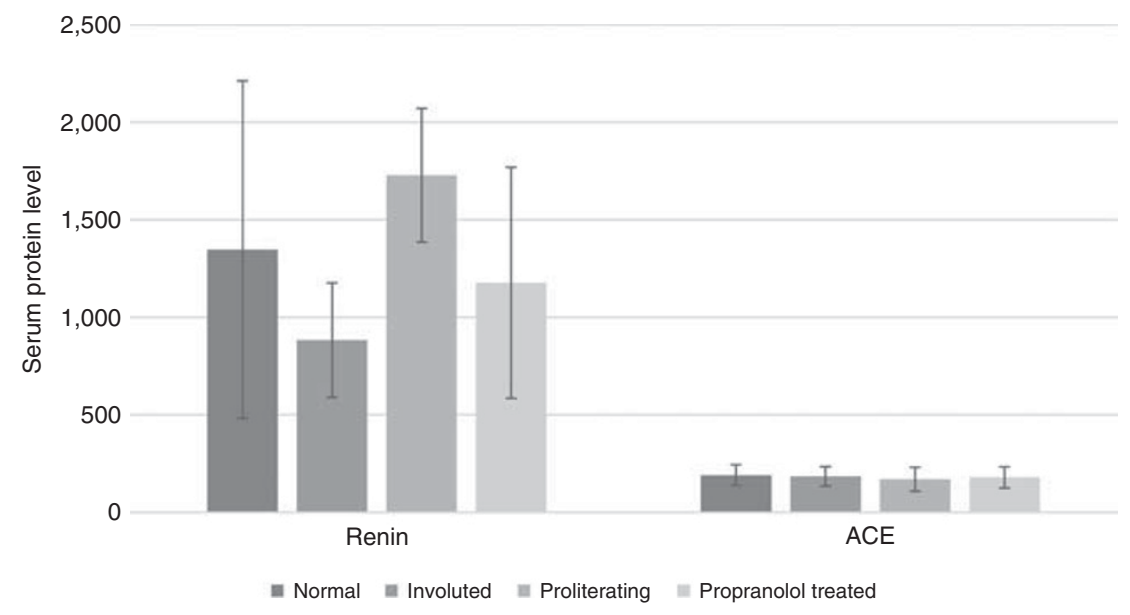

Figure 4. ELISA of RAA constituents in serum. Results show significant decreases in serum renin levels in involuting IH compared with proliferating $\mathrm{IH}$. No differences were noted in ACE levels.

mesenchymal cell hyperplasia (10-12). In addition, through some of the same pathways, AGTII has been shown to upregulate additional components of the RAA axis, perhaps resulting in a positive-feedback loop within the affected tissue $(13,14)$. This could explain some of the RAA pathway changes we saw in our results. Namely, if IH is being acted upon by the elevated levels of AGTII, in addition to stimulating hemangioma growth, AGTII should also cause an elevation of RAA pathway products, such as ACE and AGTR1, which were seen in our IH samples.

Results similar to our own have also been shown in hemangioma cell culture. Namely, at least one study demonstrated that AGTII can induce hemangioma growth, and blockade of its action can prevent or reduce hemangioma 
Table 4. Statistical analysis of ELISA analysis of RAA axis components in $I H$ and normal tissue

\begin{tabular}{|c|c|c|c|c|c|c|}
\hline \multicolumn{7}{|c|}{ Kruskal-Wallis equality-of-populations rank test for ELISA experiment } \\
\hline & All & Normal & Involuting & Proliferating & Propranolol treated & $P$ value \\
\hline \multicolumn{7}{|l|}{ Renin } \\
\hline$N$ & 31 & 8 & 8 & 8 & 7 & \\
\hline Median (IQR) & $1282.21(798.55)$ & $1187.00(611.63)$ & 907.07 (432.18) & $1778.00(549.33)$ & $996.14(810.83)$ & 0.0124 \\
\hline
\end{tabular}

ACE

$N$

Median (IQR)
32

$187.37(74.71)$
8

$172.67(93.04)$
8

$189.45(54.40)$
8

$164.01(100.20)$
8

$188.97(44.25)$

0.8979

Bonferroni-adjusted $P$ values from post hoc Dunn's pairwise comparison test

\begin{tabular}{ccccccc}
\hline & $\begin{array}{c}\text { Normal vs. } \\
\text { involuting }\end{array}$ & $\begin{array}{c}\text { Involuting vs. } \\
\text { proliferating }\end{array}$ & $\begin{array}{c}\text { Normal vs. } \\
\text { proliferating }\end{array}$ & $\begin{array}{c}\text { Involuting vs. } \\
\text { propranolol }\end{array}$ & $\begin{array}{c}\text { Normal vs. } \\
\text { propranolol }\end{array}$ & $\begin{array}{c}\text { Propranolol vs. } \\
\text { proliferating }\end{array}$ \\
\hline Renin & 0.5607 & $\mathbf{0 . 0 0 3 5}$ & 0.1628 & 0.8435 & 1.0000 & 0.1191 \\
\hline
\end{tabular}

ACE, angiotensin-converting enzyme; ELISA, enzyme-linked immunosorbent assay; IH, infantile hemangioma; IQR, interquartile range; RAA, renin-angiotensin-aldosterone Statistical significance was defined as $P<0.05$. Significant relationships in the analysis above are in bold type.

proliferation (15). Results from the same laboratory showed that excision of the tumor can reduce the levels of renin and AGTII in vivo (16). These findings support the notion that AGTII not only induces tissue growth but also modulates its own availability through the upregulation of RAA axis components. This mirrors our own results, which demonstrate a general increase in RAA axis expression in IH that is downregulated with propranolol treatment. However, our study offers an arguably more conclusive analysis of RAA axis involvement in IH by looking at both gene expression and protein level within the IH tissue itself, rather than just serum levels or culture activity, which may be subject to more confounding variables.

We thereby provide a hypothetical pathway of IH growth based upon the RAA axis that might help explain our experimental data and provide future investigational targets (Figure 5). IH tissues express RAA genes, such as $A C E$ and $A G T R 1$, at elevated levels (Figure 2). This leads to rapid cellular turnover, with the upregulation of protein levels of ACE and AGTR1 (Figure 3). These factors then act to sustain focally high levels, and/or activity, of AGTII. Increased AGTII acts to increase cell proliferation through the generation of angiogenic factors (10-12). AGTII also acts as a cofactor to upregulate RAA axis components, such as ACE and AGTR1, creating a positive-feedback loop and further driving AGTII activity in IH tissue. Propranolol can downregulate the RAA axis through its activity on beta-1-dependent renin secretion, seen as a reduction of ACE and AGTR1 levels in our study. This subsequently reduces the activity of AGTII and its direct effects on IH growth and its positive-feedback cycle. Disruption of this feedback cycle assists the early involution of IH tissue by downregulating certain proteins under control of AGTII.

This process explains several previous studies and observations, in addition to those listed above. For example, decreased downregulation of AGTII-controlled factors explains the previously discovered reductions in endothelial nitric oxide synthase, an endothelial cell mitogen and permeability factor, in both treated and involuting IH. The initial rapid reduction of IH (hours to days) to beta blockade may be explained by this phenomenon and the decrease in vasodilatory NO $(39,40)$. In addition, with this hypothetical pathway, the limited efficacy of ACE inhibitors on IH may also be explained, as dosing schedules may be unable to block the substantially increased levels of ACE in IH. Finally, this pathway could be used to explain age-related involution of IH. The physiologic reduction of renin in newborns acts similarly to the beta-1 blocker-dependent reduction of renin, but over a longer timeline. This is supported by the observed reduction of serum renin levels in involuting IH, as shown in Figure 4. At birth, high levels of renin allow for the creation of positivefeedback loops in IH tissue, which cause AGTII-mediated proliferation. As renin levels fall, levels of AGTII will decrease such that it can no longer sustain a positive-feedback loop and the tissue involutes.

The present study is limited by a small sample size and heterogeneous sample population made necessary by the influence of age and gender in the natural history and epidemiology of IH. We also did not demonstrate differences in AGTII, a protein central to the RAA pathway; however, this may be due to the very rapid breakdown of AGTII in tissue due to the activity of angiotensinase, preventing accurate detection in a processed sample (38). We have also employed a post hoc viewpoint to the experimental method to explain our differences between experimental groups. We did not directly isolate and assess the ongoing effects of the RAA pathway on IH but did demonstrate discrete 'snap-shots' of the pathway. This was made necessary due to the nature and availability of tissue samples in our institution.

Future studies are planned to modulate the pathway using IH tissue cultures supplemented with ACE, AGTR1, AGTII, and blockers of said components. This will allow a more 


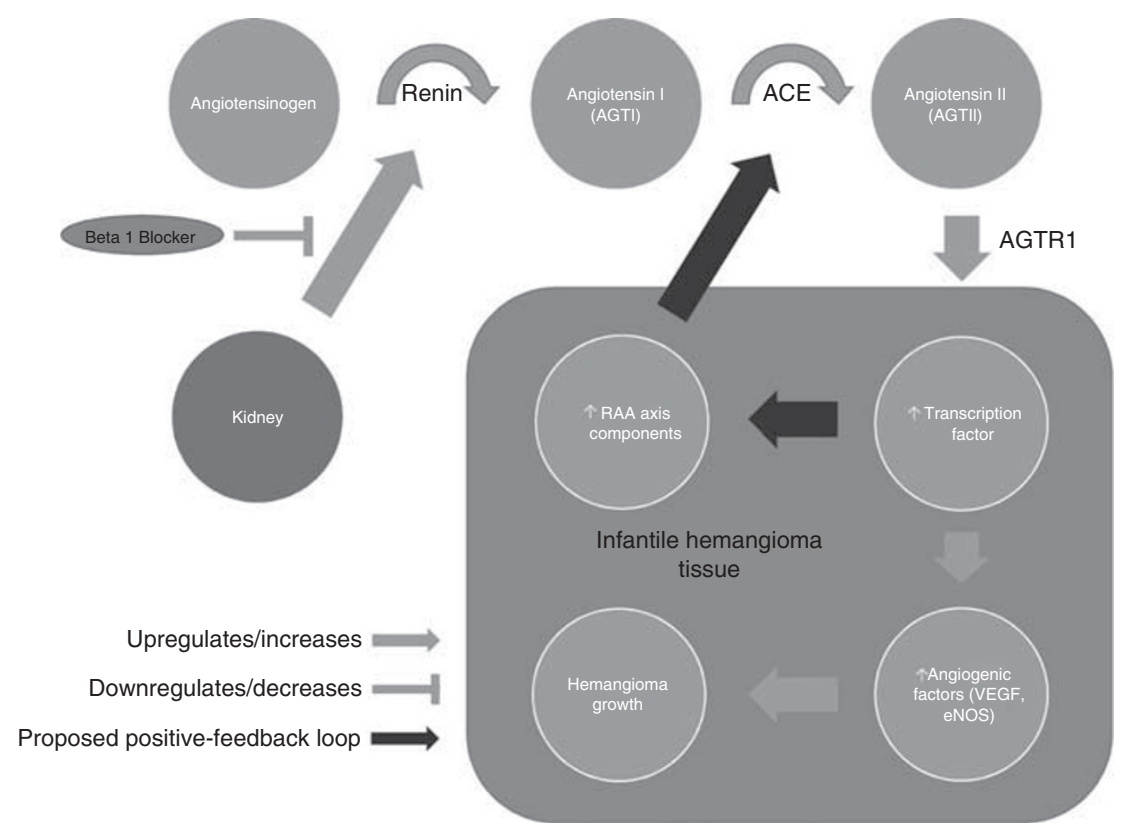

Figure 5. Hypothetical AGTII/ACE positive-feedback loop. This figure represents a simplified version of one possible pathway that helps to explain our results and identifies future targets for analysis. The key part of the cycle shown is a positive-feedback loop initiated by AGTII, as detailed by the black arrows. The cycle begins with the juxtaglomerular apparatus of the kidney secreting renin. Renin converts AGT to AGTI, which is then converted to AGTII in hemangioma tissue by high local levels of ACE. AGTIl subsequently acts through various transcription factors along two pathways: first, the transcription factors induce known angiogenic factors that cause $\mathrm{IH}$ growth, creating the clinical phenotype of $\mathrm{IH}$, and, second, some of those same transcription factors induce the expression of RAA axis components. Notable among these is ACE. This increased local level of ACE acts to create even more AGTII, creating a positive-feedback loop favoring RAA axis expression and IH growth. Treatment with a beta-1 blocker lowers the secretion of renin, which decreases the downstream levels of AGTI and AGTII, and possibly disrupts the posited feedback loop and the AGTII-induced IH growth.

effective determination of the causal relationship of RAA components with the growth of $\mathrm{IH}$ isolates and a closer examination of the levels of AGTII free of the in vitro milieu. Of note, this study examines only focally developing $\mathrm{IH}$ and not segmental $\mathrm{IH}$, which may demonstrate a wholly different process with respect to the RAA pathway.

\section{ACKNOWLEDGMENTS}

We thank Jessica Boswell for help in tissue collection and contributions to our research program.

Disclosure: The authors declare no conflict of interest.

\section{REFERENCES}

1. Haggstrom AN, Drolet BA, Baselga E, et al. Prospective study of infantile hemangiomas: demographic, prenatal, and perinatal characteristics. J Pediatr 2007;150:291-4.

2. Itinteang $\mathrm{T}$, Withers $\mathrm{AH}$, Davis $\mathrm{PF}$, Tan ST. Biology of infantile hemangioma. Front Surg 2014;1:38.

3. Ji Y, Chen S, Li K, Li L, Xu C, Xiang B. Signaling pathways in the development of infantile hemangioma. J Hematol Oncol 2014;7:13.

4. Barnés CM, Huang S, Kaipainen A, et al. Evidence by molecular profiling for a placental origin of infantile hemangioma. Proc Natl Acad Sci USA 2005;102:19097-102.

5. Richter GT, Friedman AB. Hemangiomas and vascular malformations: current theory and management. Int J Pediatr 2012;2012:645678.

6. Léauté-Labrèze CL, de la Roque ED, Hubiche T, Boralevi F, Thambo J-B, Taieb A. Propranolol for severe hemangiomas of infancy. N Engl J Med 2008;358:2649-51.
7. Buckmiller L, Dyamenahalli U, Richter GT. Propranolol for airway hemangiomas:case report of novel treatment. Laryngoscope 2009;119:2051-4.

8. Hou F, Dai Y, Dornhoffer JR, et al. Expression of endoglin (CD105) and endothelial nitric oxide synthase in head and neck arteriovenous malformations. JAMA Otolaryngol Head Neck Surg 2013;139: 237-43.

9. Takahashi K, Mulliken JB, Kozakewich HP, Rogers RA, Folkman J, Ezekowitz RA. Cellular markers that distinguish the phases of hemangioma during infancy and childhood. J Clin Invest 1994;93:2357-64.

10. Liu C, Zhang JW, Hu L, et al. Activation of the AT1R/HIF-1 $\alpha$ /ACE axis mediates angiotensin II-induced VEGF synthesis in mesenchymal stem cells. Biomed Res Int 2014;2014:627380.

11. Pagé EL, Robitaille GA, Pouysségur J, Richard DE. Induction of hypoxiainducible factor-1alpha by transcriptional and translational mechanisms. J Biol Chem 2002;277:48403-9.

12. Li P, Guo Z, Gao Y, Pan W. Propranolol represses infantile hemangioma cell growth through the $\beta 2$-adrenergic receptor in a HIF- $1 \alpha$ dependent manner. Oncol Rep 2015;33:3099-107.

13. Ide N, Hirase T, Nishimoto-Hazuku A, Ikeda Y, Node K. Angiotensin II increases expression of IP-10 and the renin-angiotensin system in endothelial cells. Hypertens Res 2008;31:1257-67.

14. Koka V, Huang XR, Chung ACK, Wang W, Truong LD, Lan HY. Angiotensin II up-regulates angiotensin i-converting enzyme (ACE), but down-regulates ACE2 via the AT1-ERK/p38 MAP kinase pathway. Am J Pathol 2008;172:1174-83.

15. Itinteang T, Marsh R, Davis PF, Tan ST. Angiotensin II causes cellular proliferation in infantile haemangioma via angiotensin II receptor 2 activation. J Clin Pathol 2015;68:346-50.

16. Sulzberger L, Baillie R, Itinteang T, de Jong S, Marsh R, Leadbitter P, Tan ST. Serum levels of renin, angiotensin-converting enzyme and angiotensin II in patients treated by surgical excision, propranolol and captopril for problematic proliferating infantile haemangioma. J Plast Reconstr Aesthet Surg 2015;69:381-6. 
17. Itinteang T, Brasch HD, Tan ST, Day DJ. Expression of components of the renin-angiotensin system in proliferating infantile haemangioma may account for the propranolol-induced accelerated involution. J Plast Reconstr Aesthet Surg 2011;64:759-65.

18. Bentley PJ. Endocrine Pharmacology: Physiological Basis and Therapeutic Applications. New York, NY: Cambridge University Press, 1980:425-8.

19. North PE, Waner M, Mizeracki A, Mihm MC. GLUT1: a newly discovered immunohistochemical marker for juvenile hemangiomas. Hum Pathol 2000;31:11-22.

20. North PE, Waner M, Mizeracki A, et al. A unique microvascular phenotype shared by juvenile hemangiomas and human placenta. Arch Dermatol 2001;137:559-70.

21. Itinteang $\mathrm{T}$, Tan ST, Guthrie S, et al. A placental chorionic villous mesenchymal core cellular origin for infantile haemangioma. J Clin Pathol 2011;64:870-4.

22. Itinteang $\mathrm{T}$, Tan ST, Brasch HD, et al. Infantile haemangioma expresses embryonic stem cell markers. J Clin Pathol 2012;65:394-8.

23. Bauland CG, Smit JM, Bartelink LR, Zondervan HA, Spauwen PHM. Hemangioma in the newborn: increased incidence after chorionic villus sampling. Prenat Diagn 2010;30:913-7.

24. Burton BK, Schulz CJ, Angle B, Burd LI. An increased incidence of haemangiomas in infants born following chorionic villus sampling (CVS). Prenat Diagn 1995;15:209-14.

25. Waner M, North PE, Scherer KA, Frieden IJ, Waner A, Mihm Jr MC . The nonrandom distribution of facial hemangiomas. Arch Dermatol 2003;139:869-75.

26. Pan N, Frome WL, Dart RA, Tewksbury D, Luo J. Expression of the reninangiotensin system in a human placental cell line. Clin Med Res 2013;11:1-6.

27. Pringle KG, Tadros MA, Callister RJ, Lumbers ER. The expression and localization of the human placental prorenin/renin-angiotensin system throughout pregnancy: roles in trophoblast invasion and angiogenesis? Placenta 2011;32:956-62.

28. Anton L, Brosnihan KB. Systemic and uteroplacental renin-angiotensin system in normal and pre-eclamptic pregnancies. Ther Adv Cardiovasc Dis 2008;2:349-62.
29. Stephenson TJ, Broughton Pipkin F, Elias-Jones AC. Factors influencing plasma renin and renin substrate in premature infants. Arch Dis Child 1991;66 (10 Spec No): 1150-4.

30. Shah DM. Role of the renin-angiotensin system in the pathogenesis of preeclampsia. Am J Physiol Renal Physiol 2005;288:F614-25.

31. Irani RA, Xia Y. The functional role of the renin-angiotensin system in pregnancy and preeclampsia. Placenta 2008;29:763-1.

32. Fiselier T, Lijnen $\mathrm{P}$, Monnens L, Munster PV, Jansen M, Peer P. Levels of renin, angiotensin I and II, angiotensin-converting enzyme and aldosterone in infancy and childhood. Eur J Pediatr 1983;141:3-7.

33. Dillon MJ, Ryness JM. Plasma renin activity and aldosterone concentration in children. Br Med J 1975;4:316-9.

34. Bauer JH. Age-related changes in the renin-aldosterone system. Physiological effects and clinical implications. Drugs Aging 1993;3: 238-45.

35. Dillon MJ, Gillin ME, Ryness JM, de Swiet M. Plasma renin activity and aldosterone concentration in the human newborn. Arch Dis Child 1976;51:537-40.

36. Chang LC, Haggstrom AN, Drolet BA, et al. Growth characteristics of infantile hemangiomas: implications for management. Pediatrics 2008;122:360-7.

37. Graaf MD, Raphael M, Breugem C, et al. Treatment of infantile haemangiomas with atenolol: comparison with a historical propranolol group. J Plast Reconstr Aesthet Surg 2013;66:1732-40.

38. Tan ST, Itinteang T, Day DJ, O’Donnell C, Mathy JA, Leadbitter P. Treatment of infantile haemangioma with captopril. Br J Dermatol 2012;167:619-24.

39. Dai Y, Hou F, Buckmiller L, et al. Decreased eNOS protein expression in involuting and propranolol-treated hemangiomas. Arch Otolaryngol Head Neck Surg 2012;138:177-82.

40. Zheng J, Wen Y, Chen DB, Bird IM, Magness RR. Angiotensin II elevates nitric oxide synthase 3 expression and nitric oxide production via a mitogen-activated protein kinase cascade in ovine fetoplacental artery endothelial cells. Biol Reprod 2005;72:1421-8. 